9 - ORIGINAL ARTICLE

WOUND HEALING

\title{
Inflammatory reaction and tensile strength of the abdominal wall after an implant of polypropylene mesh and polypropylene/poliglecaprone mesh for abdominal wall defect treatment in rats ${ }^{1}$
}

\author{
Maria de Lourdes Pessole Biondo-Simõesi, Paula Almeida Pamponet Moura ${ }^{\mathrm{II}}$, Kelly Colla", Anna Flávia Zonato Tocchio ${ }^{\mathrm{II}}$, \\ Camila Gomes de Morais", Renata Augusta de Miranda", Rogério Ribeiro Robes ${ }^{\text {III }}$, Sérgio Ossamu Ioshii ${ }^{\text {IV }}$
}

DOI: http://dx.doi.org/10.1590/S0102-86502014001300009

${ }^{\mathrm{I}} \mathrm{PhD}$, Associate Professor, Department of Surgery, Federal University of Paraná (UFPR), Parana, Brazil. Concept, design, acquisition, analysis and interpretation of data; critical review of the study.

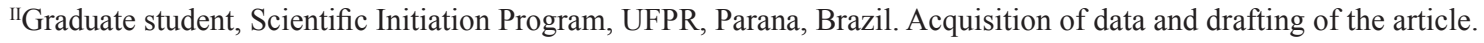

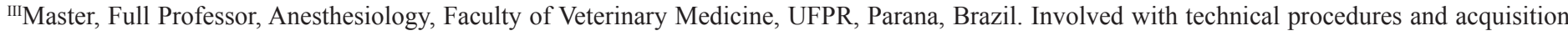
of data.

${ }^{\text {IV }} \mathrm{PhD}$, Associate Professor, Division of Pathology, PUCPR and Associate Professor, Division of Pathology, UFPR, Parana, Brazil. Pathology data interpretation.

\begin{abstract}
PURPOSE: To compare the inflammatory reaction and the growing resistance of the abdominal wall with the use of poliglecaprone meshes and polypropylene meshes associated with poliglecaprone in the correction of abdominal defects.

METHODS: Seventy-seven Wistar rats were divided into three groups: CG (non-operated animals: EG (polypropylene mesh) and UG (polypropylene and poliglecaprone mesh). A muscular and aponeurotic defect was formed and treated according to the group. Evaluations were made after 4, 7, 14, 28 and 56 days. The resistance and inflammatory pattern were studied.

RESULTS: There was a gradual and significant gain in resistance, regularly in the EG and irregularly in the UG, which was lower on the $14^{\text {th }}$ day $(p=0.008)$. The inflammatory reaction was acute and more intense in the UG on the fourth day. At all other times, the inflammatory pattern was acute to chronic, similar in both groups, with minimum intensity on the $56^{\text {th }}$ day.

CONCLUSION: The greater resistance offered by the polypropylene mesh was regular and ascending, stabilizing on the $28^{\text {th }}$ day, while that of the polypropylene/poliglecaprone was not even. In the end, the resistances were similar. The inflammatory response was greater in the UG on the fourth day and similar at all other times.
\end{abstract}

Key words: Surgical mesh. Hernia. Ventral hernia. Wound healing. Inflammation. 


\section{Introduction}

Incisional hernias, also known as ventral hernias or eventrations, occur when tissues protrude through openings or areas of an abnormal abdominal wall due to a trauma or wound ${ }^{1}$. They occur following a laparotomy with a frequency estimated between $10 \%$ and $20 \%{ }^{2}$. Between $31 \%$ and $55 \%$ of repairs for hernias without prostheses can lead to a relapse ${ }^{3,4}$. A considerable proportion of patients suffer incarceration or strangulation, requiring emergency abdominal surgery ${ }^{5}$.

The first surgery to correct hernias using polypropylene meshes was performed by Usher et al. ${ }^{6}$. Surgical meshes are currently considered the gold standard treatment for herniorrhaphies ${ }^{7}$, with the polypropylene mesh being the most commonly used ${ }^{4}$.

The mesh functions as a framework, and its architecture is composed of entwined threads and pores, through which the cells of the host permeate the fabric. Fibrous scar tissue forms around the fibers of the mesh, enabling it to adhere to the tissues of the host ${ }^{4}$. The larger the diameter of the pores, the larger the inflammatory cells will be, and the healing process will be faster. The tissue reaction usually begins with a considerable inflammatory process in the entire area of the mesh ${ }^{8}$.

Polypropylene meshes are characterized as inert to infection, low in cost and flexible. They maintain the strength of the abdominal wall, with an excellent capacity for integration ${ }^{8}$. However, they can provoke an intense inflammatory reaction, which results in reduced elasticity of the wall ${ }^{4}$.

Meshes with a large quantity of material can cause intense inflammatory reactions of foreign bodies, with reduced complacency of the tissue and imprisoned surrounding neural structures, leading to chronic pain, rigidity of the abdominal wall and intra-abdominal adhesion ${ }^{9,10}$.

Several strategies have been employed to avoid complications. One solution is to limit the amount of polypropylene in the mesh or use absorbable materials, which will provide initial strength and then be absorbed, reducing the local inflammatory reaction the reaction of the foreign body ${ }^{11}$. A point in question is the polypropylene mesh associated with poliglecaprone, created to leave $65 \%$ fewer foreign bodies in the organism compared to traditional meshes and to provide four times greater resistance to maximum abdominal pressure ${ }^{12}$.

A meta-analysis shows that polypropylene meshes with an absorbable component produced a better response in the host in terms of adhesion of the connective tissue and inflammatory reaction ${ }^{13}$.

There is no consensus regarding the best material to use in surgical meshes. Ideally, they should be resistant to traction, not be carcinogenic and be inert, stable in the case of infection, capable of developing inflammatory reactions of the tissue and avoid rejection ${ }^{14}$.

The aim of this study is to compare the inflammatory reaction and the increased resistance of the abdominal wall using polypropylene meshes and polypropylene/poliglecaprone meshes to correct abdominal defects in rats.

\section{Methods}

The study was analyzed by the Ethics Committee on the Use of Animals in Health Sciences of the Federal University of Paraná (UFPR) and assigned Process number 23075.038580/201281 and approved as case 650, on 1 November, 2012, R.O. 10/2012, in accordance with Federal Law 11.794, of 8 October, 2008, which establishes the procedures for the scientific use of animals and guidelines from the Brazilian College of Animal Experiments (COBEA).

Seventy-seven Wistar rats (Rattus norvegicus albinus, Rodentia mammalia) were used, provided by the Central Vivarium of the Federal University of Paraná. The rats were all male. They were 140 days old and their average weight was $422.54 \pm 64.19 \mathrm{~g}$.

Housed in polypropylene boxes of appropriate dimensions for the species, with five animals per box, they remained at the Vivarium for the Discipline of Surgical Technique and Experimental Surgery of the UFPR. The dark/light cycle was 12 hours and the room temperature and humidity were those of the general environment, with no artificial regulation. The animals had free access to water and standard commercial food.

The rats were divided into three study groups: the default group (CG), with seven rats, the polypropylene group (EG) and the polypropylene/poliglecaprone (UG), with 35 rats each. The two latter were subdivided into four groups of seven. In each of these, euthanasia was practiced in one of the periods of four, seven, fourteen, twenty-eight and fifty-six days following surgery.

For the surgical procedure, the animals were given a general anesthetic by a veterinary surgeon. An intra-muscular injection of $0.1 \mathrm{ml} / 100 \mathrm{~g}$ of weight of a solution of $1.0 \mathrm{ml} \mathrm{de}$ Ketamine $(50 \mathrm{mg} / \mathrm{ml})$ and $1.0 \mathrm{ml}$ de xylazine $(20 \mathrm{mg} / \mathrm{ml})$ associated with $20 \mathrm{mg} / \mathrm{kg}$ of intraperitoneal thionembutal.

Intramuscular dypirone was given as an analgesic, at a dose of $10 \mathrm{mg} / \mathrm{kg}$, immediately after recovery from the anesthetic.

Once the rats had been anesthetized, weighed and marked, their ventral abdominal walls were trichotomized. Antisepsis was done with polyvinylpyrrolidone iodine. 
A median incision was made of approximately four centimeters of the skin and the subcutaneous mesh. A muscular and aponeurotic fragment was removed from the abdominal wall, with a diameter of 1.5 centimeters, preserving the integrity of the parietal peritoneum (Figure 1). A mesh of 2.5 centimeters in diameter was introduced to the defect, according to the group to which each animal belonged in a pre-peritoneal situation. The mesh was attached with eight separate stiches of polypropylene 4.0 (Figure 1).
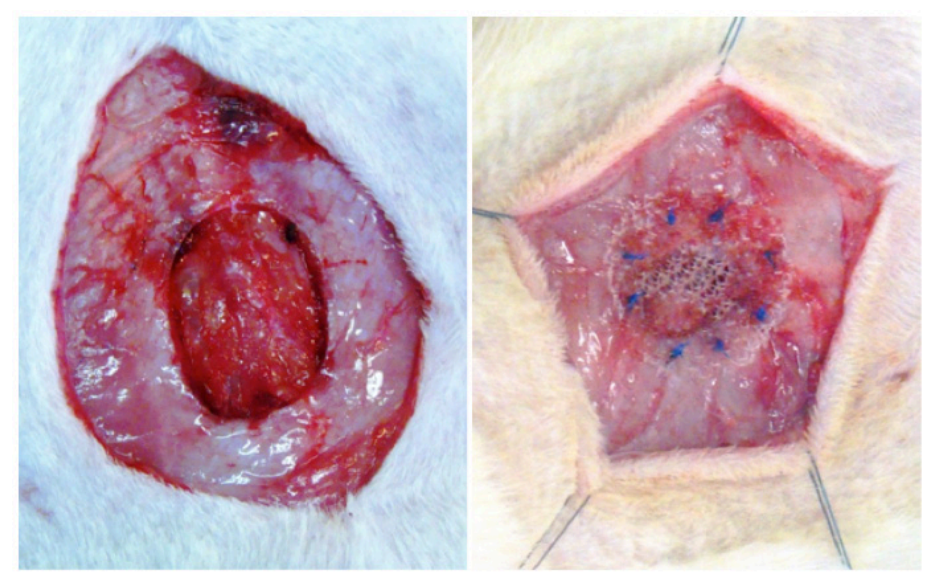

FIGURE 1 - View of the muscular-aponeurotic defect, maintaining the integrity of the peritoneum on the left and followed by the implantation of the mesh.

For the EG, a polypropylene mesh of $180 \mu$ (Marlex ${ }^{\circledR}$, Cirúrgica Brasil) was used. This mesh is non-absorbable and has high density, with pores that average 0.8 and an estimated weight of $100 \mathrm{~g} / \mathrm{m}^{2}$. For the UG, a mixed polypropylene and polilgecaprone mesh (Ultrapro ${ }^{\circledR}$, Johnson \& Johnson International, C/O European Logistic Centre, Belgium) was used. This mesh is low density and partially absorbable, with pores measuring over $3.0 \mathrm{~mm}$ and an estimated weight of $28 \mathrm{~g} / \mathrm{m}^{2}$.

This was followed by a skin synthesis, with the application of a continuous suture of nylon monofilament 4.0.

Having recovered from the anesthetic and been given the analgesic, the animals were returned to their boxes, where they remained until the day of their euthanasia, under the same environmental and feeding conditions they had experienced prior to the surgery.

Euthanasia was performed at predetermined times with a lethal dose of intra-peritoneal thionembutal $(120 \mathrm{mg} / \mathrm{kg})$ in accordance with the guidelines of Resolution 1000 of the Federal Council of Veterinary Medicine of 11 May, 2012.

For the necropsy, a new laparotomy was conducted and a macroscopic analysis was made of the region under study, observing the presence of secretions and whether the integrity of the corrected area was maintained.
A segment of the abdominal wall measuring $6.0 \mathrm{~cm}$ in width and $4.0 \mathrm{~cm}$ in length was removed with the implanted mesh.

This segment was divided in two equal parts transversally. The cranial half was kept and extended on a paper filter in a physiological solution and immediately sent for tensiometry. The caudal half was also extended on a paper filter and set in formaldehyde $10 \%$ and was used for the histological study.

The analysis of the resistance of the abdominal wall was conducted using the EMIC DL-500 $\mathrm{MF}^{\circledR}$ Extensometer and MTest EMIC ${ }^{\circledR}$ software, which provided the values pertaining to the resistance of the wall in the standard group and the groups with polypropylene and polypropylene/poliglecaprone. The walls of the standard group were measured without being submitted to any intervention, seeking the value of the normal resistance of these animals, serving as a means of comparison with the gains in resistance of the corrected walls.

For the analysis of the inflammatory reaction, the fragments were blocked in paraffin using the conventional technique. From these blocks cuts were obtained with a thickness of five micrometers. These were mounted on blades and colored with hematoxylin and eosin.

To classify and quantify the inflammatory reaction, the type and quantity of predominant cells were evaluated (monomorphonuclear and polymorphonuclear infiltrates), along with interstitial edema, vascular congestion and granulation and fibrosis tissue, in accordance with the model described by Vizzotto Jr et al. ${ }^{15}$.

The data enabled the classification of the reaction as intense, moderate, discreet and absent, according to the degree of intensity found. The data were transformed into quantitative variables following the attribution of the indices to the histological findings. The edema, congestion and neutrophilic exudate were indicative of an acute inflammatory process. The granulation tissue, fibrosis tissue and the monomorphonuclear exudate were indicative of a chronic inflammatory process. A negative sign was attributed to the indexes of the inflammatory process, and a positive sign was attributed to the chronic inflammatory process (Table 1). This evaluation was conducted in five fields in order to obtain a median.

To count the monomorphonuclears (MMN) and the polymorphonuclears $(\mathrm{PMN})$, fibrosis and vascularization, scores were given (Table 2). Following the attribution of the indexes, the sum was calculated so that each wall had a final score, thus enabling the inflammatory process to be classified in three phases (Table 3). 
TABLE 1 - Classification and attribution of indexes to the histological findings in the histological cuts colored by hematoxylin and eosin.

\begin{tabular}{ccccc}
\hline $\begin{array}{c}\text { Inflammatory } \\
\text { Parameters }\end{array}$ & Intense & Moderate & Discreet & Absent \\
\hline Polymorphonuclears & -3 & -2 & -1 & 0 \\
Edema & -3 & -2 & -1 & 0 \\
Congestion & -3 & -2 & -1 & 0 \\
Monomorphonuclears & 3 & 2 & 1 & 0 \\
Granulation tissue & 3 & 2 & 1 & 0 \\
Fibrosis & 3 & 2 & 1 & 0 \\
\hline
\end{tabular}

Fonte: Vizzotto Junior AO, Noronha L, Scheffel DLH, Campos AC. Influência da cisplatina administrada no pré e no pós-operatório sobre a cicatrização de anastomoses colônicas em ratos. J Bras Patol Med Lab. 2003;39(2):143-9.

TABLE 2 - Scores for the reading of PMN, MMN, fibrosis and vessels for each field of reading.

\begin{tabular}{c|c|c|c|c|c}
\hline $\begin{array}{c}\text { PMN } \\
\text { and } \\
\text { MMN }\end{array}$ & Score & Fibrosis & Score & $\begin{array}{c}\text { Vessels } \\
\text { / field }\end{array}$ & Score \\
$0-20$ & 0 & fibrosis > cellularity & 3 & 0 & 0 \\
$20-50$ & 1 & fibrosis = cellularity & 2 & 1 a 2 & 1 \\
$50-100$ & 2 & fibrosis < cellularity & 1 & 3 a 8 & 2 \\
100 & 3 & no fibrosis & 0 & $>8$ & 3 \\
\hline
\end{tabular}

TABLE 3 - Inflammation score.

\begin{tabular}{cc}
\hline Phases of the Inflammatory & Final classification score \\
\hline Process & \\
Acute & -9 a -3 \\
Acute-chronic & -2.9 a +3 \\
Chronic & +3.1 a +9 \\
\hline
\end{tabular}

Fonte: Vizzotto Junior AO, Noronha L, Scheffel DLH, Campos AC. Influência da cisplatina administrada no pré e no pós-operatório sobre a cicatrização de anastomoses colônicas em ratos. J Bras Patol Med Lab. 2003;39(2):143-9.

For the statistical analysis, the median, the standard deviation and the maximum and minimum values were used. For the evaluation of these data between groups at different times, the non-parametric Mann Whitney test was used, and for the intragroup evaluation, the Kruskal-Wallis was used. For the frequency analysis, Fisher's exact test was used. The level of rejection for the null hypothesis was set at $\mathrm{p} \leq 0.05$ or $5 \%$.

\section{Results}

One animal died during anesthesia. During the observation period, the loss of six animals was registered, one from the polypropylene group (EG) and five from the polypropylene/ poliglecaprone group (UG), having lost their skin synthesis, which would compromise the analysis. For the analysis, 34 animals from the EG and 30 from the UG remained.

No macroscopic abscesses were found and the syntheses of the meshes were intact during evaluation. There were no intracavity adhesions.

On the fourth day evaluation, the resistance of the wall in the UG was less resistance than that of the CG $(66.53 \%$ of the resistance of the CG). The same observation was observed in the resistance of the EG (69.83\% of the resistance of the CG) $(p=0.931)$.

Both groups showed a gain in resistance over time. The curve of the EG was upward and that of the UG was initially downward, showing a drop on the $14^{\text {th }}$ day $(\mathrm{p}=0.008)$, but turned upward again. On the $56^{\text {th }}$ day, the median resistance of the UG walls rose to $93.40 \%$ of the resistance of the $\mathrm{CG}$, and the walls of the EG reached $92.15 \%(\mathrm{p}=0.876)$ (Figure 2).

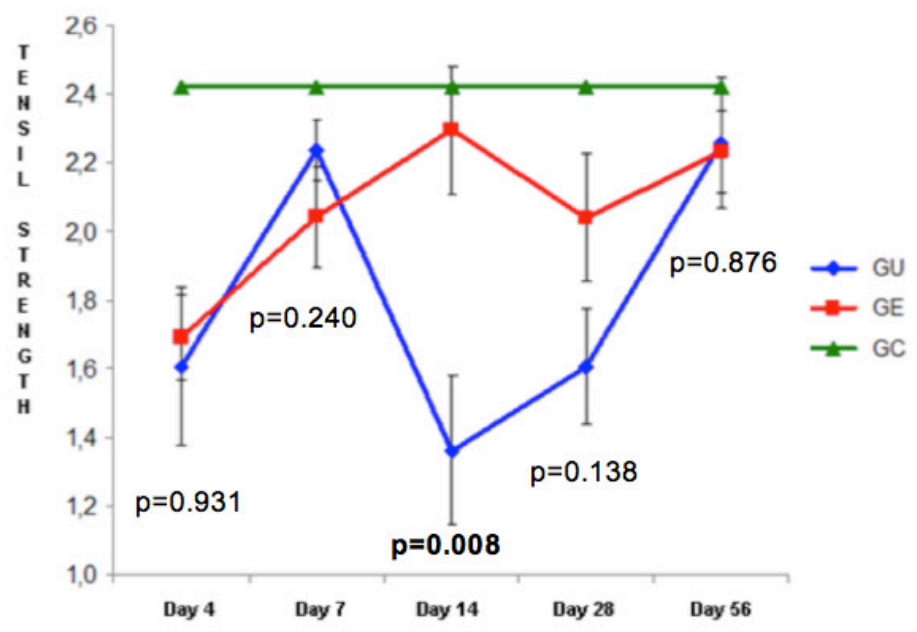

FIGURE 2 - Graphic demonstration of the medians and standard deviations of gains in resistance (Newton) of both groups, compared with the normal pattern.

Note: the $p$ values refer to the comparison between the UG and EG (Mann Whitney Test)

A microscopic examination showed on the fourth day that in the UG the acute inflammatory reaction was predominant $(p=0.0454)$. It was more intense and a microabscess had been found. On the seventh day, the inflammatory reaction was acutechronic and moderately intense in both groups (Figure 3). On the $14^{\text {th }}$ day, the acute inflammatory reaction was predominant in both groups ( $p=0.3426)$, and moderately intense. The same occurred on the $28^{\text {th }}$ day $(p=0.9696)$. On the $56^{\text {th }}$ day the inflammatory reaction remained acute-chronic and was discreet in both groups $(p=1)$ (Figure 4). An analysis of the cuts showed, from the seventh day onward, the presence of foreign-body giant cells, with the same frequency in both groups. 


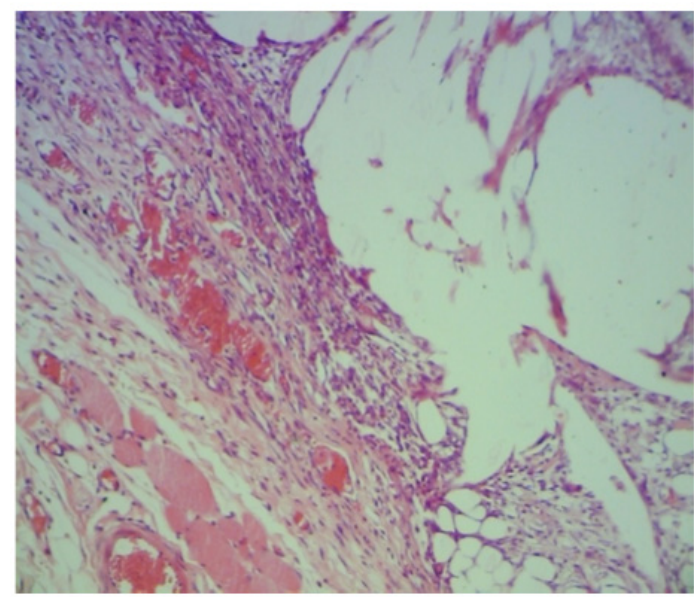

FIGURE 3 - Photomicrograph of histological cut with septa of the wall of the EG on the seventh day, showing moderately intense inflammatory infiltration and vascular congestion ( $\mathrm{HE}-\mathrm{x} 400)$.

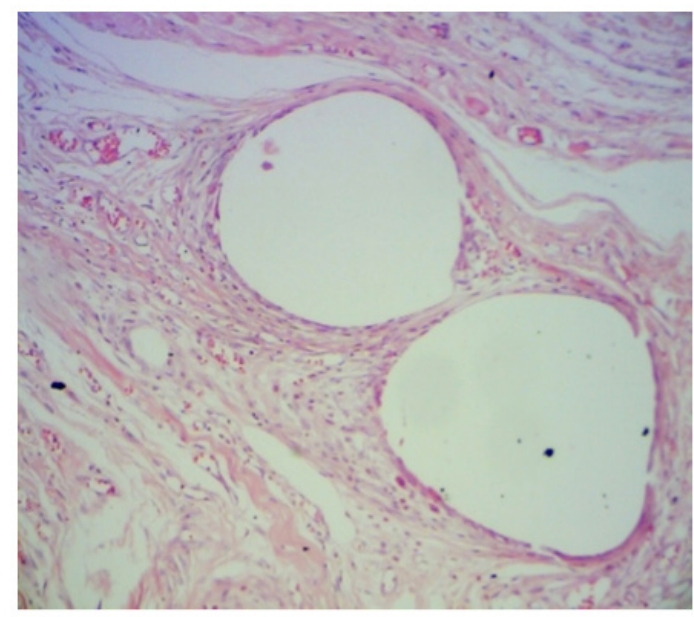

FIGURE 4 - Photomicrograph of a histological cut of the wall of the EG after 56 days, with discreet inflammatory reaction (HE - x200).

\section{Discussion}

The correction of incisional abdominal hernias remains one of the most common surgical procedures, given its expressive rate of occurrence following a laparotomy ${ }^{16}$.

The abdominal wall is a muscular structure under a dynamic equilibrium of loading forces that is disturbed after a laparotomy. Although the adjacent rectus muscles retain their origin and insertion, the insertion of the oblique muscles is lost after a median laparotomy and the formation of an incisional hernia. The linea alba of the abdominal wall is anatomically a tendon which induces muscular alterations to the wall, when cut ${ }^{17}$. Dubay et al. studied the modification of the abdominal musculature in rats induced with the formation of a median incisional hernia. After 35 days the researchers observed a shortening and atrophy of the oblique muscles associated with a modified arrangement of their fibers, consistent fibrosis and atrophic myopathy. These muscles showed a significant reduction in their extensibility and rigidity ${ }^{17}$.

Atrophy of the musculature and shortened fibers make the closure of these defects, when a fascial suture is used, increase the tension, which can result in a relapse. Repairing with a mesh minimizes the tension and meshes are thus generally preferable for treating incisional hernias ${ }^{16}$.

There are synthetic prosthetics, such as polypropylene, polyglactin and poliglecaprone and polytetrafluoroethyle meshes. These can be of a single material or a combination of materials. There are also natural biomaterials such as bovine parietal peritoneum and porcine small intestinal submucosa. Synthetic prosthetics contain meshes with pores of variable sizes. For adequate infiltration of the inflammatory cells, fibroblasts and angiogenic cells, the pores should be larger than $75 \mu \mathrm{m}$. Larger pores allow for less foreign material to be left and enable a lighter and more flexible mesh ${ }^{18}$.

The polypropylene mesh is the most commonly used and has pores with an average size of $0.8 \mathrm{~mm}$ and an average weight of $100 \mathrm{~g} / \mathrm{m}^{2}$, which means that it is among the heavier meshes ${ }^{18}$. Larger pores enable meshes to weigh less. Combining polypropylene with poliglecaprone threads results in meshes with larger pores of three millimeters and a weight of $28 \mathrm{~g} / \mathrm{m}^{2}$. Polypropylene threads help to maintain the rigid structure, enabling easier intra-operational handling ${ }^{18}$. The advantage is that the absorbable component (poliglecaprone) provides good biological compatibility and the reduced amount of non-absorbable material leads to fewer foreign-body reactions, minimizing complications that result from the classic polypropylene mesh ${ }^{19}$.

For this study, the same breed of Wistar rats was used, with the same gender, age and origin in order to exclude individual attributes such as hormonal alterations and growth, which could impact the inflammatory reaction and affect the results. Likewise, the same systematization was used for the surgical procedure, which was conducted by a single researcher to ensure homogeneity of the technique.

During the macroscopic analysis, no abscesses, suture dehiscence of the meshes or intra-cavity adhesion were observed. Utrabo et al. evaluated the healing of defects in the abdominal wall in 30 rats after the use of polypropylene and polypropylene/ poliglecaprone meshes and found intra-abdominal adhesions in four animals, even with the extraperitoneal location of the meshes ${ }^{4}$. These adhesions may have occurred due to small lesions of the parietal peritoneum, which is very short in this species of animal or because it caused a greater inflammatory reaction, compromising this plane of the abdominal wall. In the study conducted by these authors, no hematomas, infections, fistulae or suture dehiscence 
were registered ${ }^{4}$.The rupture occurred outside of the suture line. This is explained by the fact that the prosthetics had a breaking point that was more resistant than that of the abdominal wall.

The resistance offered by the corrected walls in both groups was similar in intensity at the end of the process $(p=0.876)$. However, an analysis of the gain curve showed that the walls treated with polypropylene mesh gained resistance until the 14th day and then stabilized. The walls that received polypropylene / poliglecaprone meshes initially gained resistance, but there was a considerable drop on the 14th day. By the 56th days, these walls had similar results to those treated with polypropylene.

This could be justified by the fact that the EG walls had a non-absorbable mesh and thus resistance would be made by the mesh and the synthesized fibrotic tissue. Because the meshes were partially absorbable, the walls of the UG could offer resistance depending much more on the connective fibrotic tissue than on the mesh itself. This irregularity may have to do with the inflammatory reaction and even with the absorbable fraction of the mesh. Junge et al. described the first histological signs of reabsorption of poliglecaprone threads on the 56th day ${ }^{20}$. These authors studied histological behavior and did not relate it to resistance. In the present study, there was no microscopic study of the existence of fragmentation of the threads but, macroscopically, the meshes were intact.

In the study conducted by Bellón et al. ${ }^{21}$, the evaluation of resistance to traction was similar on both occasions under study, the fourteenth and the ninetieth days. In the case of Utrabo et $a l .{ }^{4}$, the tensiometry showed a significant difference between the polypropylene and the polypropylene/poliglecaprone groups when analyzing the force of the rupture of the abdominal wall after sixty days, with the force being greater in the polypropylene/ poliglecaprone. These findings diverge from those of Bellón et $a l{ }^{21}$ and the results of the present study.

The healing process is characterized by homeostasis, inflammation, the formulation of granulation tissue, reepithelialization and remodeling of the extracellular matrix. During the inflammatory phase, the migration of cells such as neutrophils, lymphocytes and macrophages is fundamental for regulating the repair process, as they secrete cytokines, lymphokines and growth factors, which act as molecular beacons ${ }^{22}$.

Although the phagocytosis of the macrophages is inefficient for degrading the prosthetic, these cells coalesce, forming giant cells that surround the biomaterial. Chronic reactivations of the inflammatory process can occur, which explains the longterm complication ${ }^{22}$. Mast cells have been considered as critical effectors in the induction of inflammatory and fibrotic reactions ${ }^{23}$.
The inflammatory reaction caused by the polypropylene/ poliglecaprone mesh was greater on the fourth day, and at all other times matched the reaction caused by the polypropylene mesh, which leads to the assumption that this mesh initially provokes a greater reaction. This can explain the irregularity in the resistance gain.

The predominance of moderately intense acute-chronic inflammatory reactions was registered between the seventh and the $28^{\text {th }}$ day. Utrabo et al. found a subacute inflammatory reaction in their analysis of the $30^{\text {th }}$ day following surgery in both groups. Their analysis on the sixtieth day showed a chronic inflammatory process ${ }^{4}$. This finding diverges from the present findings, which classify the reactions as acute-chronic and of discreet intensity on the $56^{\text {th }}$ day.

Bellón et al. ${ }^{21}$ compared meshes in implants, albeit intrperitoneal implants in rabbits. They observed that the percentage of macrophages was reduced between 14 and 90 days after the implant with no significant differences in the median counts of macrophages for polypropylene and polypropylene/ poliglecaprone meshes. They considered this result important because it indicated that even though biodegradable materials induced a greater foreign-body reaction initially, this reaction would be terminated by the $90^{\text {th }}$ day after the implant.

Binnebosel et al..$^{24}$ compared heavyweight polypropylene meshes with heavyweight polypropylene/poliglecaprone meshes using the onlay and sublay techniques in chinchillas. They obtained a higher number of foreign-body granulomas on the side facing the abdominal wall in heavyweight polypropylene implants in relation to those associated with poliglecaprone.

Pascual et al. analyzed the inflammatory reaction and the tissue maturation in the incorporation of polypropylene meshes of different weights and associated absorbable material. They observed that they all induced an inflammation involving macrophages and foreign-body giant cells, but that these reactions were more intense with polypropylene/poliglecaprone meshes ${ }^{11}$. A meta-analysis of 38 publications showed that polypropylene meshes when associated with absorbable material had a higher infiltration of monocytes/macrophages when compared with pure polypropylene meshes ${ }^{13}$. This information is contradictory.

In this study, although the resistance gain curves showed different behaviors, this did was not connected to the quality or even the intensity of the inflammatory reaction.

\section{Conclusions}

The gain curve of resistance for the walls that were corrected using a polypropylene mesh is evenly spread 
and ascendant, while those corrected with polypropylene/ poliglecaprone are irregular. At the end of the observation period, both offered the same resistance. The local inflammatory reaction was greater in the UG on the fourth day and similar to the other two groups at all other times.

\section{References}

1. Aramayo ALG, Filho GJL, Barbosa CA, Amaral VF, Costa LA. Abdominal wall healing in incisional hernia using different biomaterials in rabbits. Acta Cir Bras. 2013;28(4):307-16.

2. Schreinemacher MHF, Emans PJ, Gilbels MJJ, Greve JWM, Beets GL, Bouvy ND. Degradation of mesh coatings and intraperitoneal adhesion formation in an experimental model. $\mathrm{Br} \mathrm{J}$ Surg. 2009;96(3):305-13.

3. Gaertner WB, Bonsack ME, Delaney JP. Visceral adhesions to hernia prostheses. Hernia. 2010;14(4):375-81.

4. Utrabo CAL, Czeczko NG, Busato CR, Montemor-Netto MR, Malafaia O, Dietz UA. Comparative study between polypropylene and polypropylene/poliglecaprone meshes used in the correction of abdominal wall defect in rats. Acta Cir Bras. 2012;27(4):300-5.

5. Cassar K, Munro A. Surgical treatment of incisional hernia. Br J Surg. 2002;89(5):534-45.

6. Bringman S, Conze J, Cuccurullo D, Deprest J, Junge K, Klosterhalfen B, Parra-Davila E; Ramshaw B; Schumpelick V. Hernia repair: the search for ideal meshes. Hernia 2010;14(1):81-7.

7. Moretti AI, Pinto FJ, Cury V, Jurado MC, Marcondes W, Velasco IT, Souza HP. Nitric oxide modulates metalloproteinase-2, collagen deposition and adhesion rate after polypropylene mesh implantation in the intra-abdominal wall. Acta Biomater. 2012;8(1):108-15.

8. Vaz M, Krebs RK, Trindade EN, Trindade MRM. Fibroplasia after polypropylene mesh implantation for abdominal wall hernia repair in rats. Acta Cir. Bras. 2009;24(1):19-25.

9. Hollinsky C, Sandberg S, Koch T, Seidler S. Biomechanical properties of lightweight versus heavyweight meshes for laparoscopic inguinal hernia repair and their impact on recurrence rates. Surg Endosc. 2008;22(12):2679-85.

10. Currie A, Andrew H, Tonsi A, Hurley PR, Taribagil S. Lightweight versus heavyweight mesh in laparoscopic inguinal. Surg Endosc. 2012;26(8):2126-33.

11. Pascual G, Rodríguez M, Sotomayor S, Pérez-Köhler B, Bellón JM. Inflammatory reaction and neotissue maturation in the early host tissue incorporation of polypropylene prostheses. Hernia. 2012;16(6):697-707.

12. Grevious MA, Cohen M, Jean-Pierre F, Herrmann GE. The use of prosthetics in abdominal wall reconstruction. Clin Plast Surg. 2006;33(2):181-97.

13. Huber A, McCabe GP, Boruch AV, Medberry C, Honerlaw M, Badylak SF. Polypropylene-containing synthetic mesh devices in soft tissue repair: a meta-analysis. J Biomed Mater Res B Appl Biomater. 2012;100(1):145-54

14. Jin J, Voskerician G, Hunter SA, McGee MF, Cavazzola LT, Schomish S, Harth K, Rosen MJ. Human peritoneal membrane controls adhesion formation and host tissue response following intra-abdominal placement in a porcine model. J Surg Res. 2009;156(2):297-304.
15. Vizzotto Junior AO, Noronha L, Scheffel DLH., Campos ACL. Influência da cisplatina administrada no pré e no pós-operatório sobre a cicatrização de anastomoses colônicas em ratos. J Bras Patol Med Lab. 2003;39(2):143-9.

16. Speranzini MB, Deutsch CR. Grandes Hérnias Incisionais. ABCD. 2010;23(4):280-6.

17. DuBay DA, Choi W, Urbanchek MG, Wang X, Adamson B, Dennis RG, Kuzon WM, Franz MG. Incisional herniation induces decreased abdominal wall compliance via oblique muscle atrophy and fibrosis. Ann Surg. 2007;245(1):140-6.

18. Brown CN, Finch JG. Which mesh for hernia repair? Ann R Coll Surg Engl. 2010;92(4):272-8.

19. Paulo NM, Malnoge SM, Borges de Menezes L, Gontijo de Lima F, Faria AM, Andrasckho MM, Moreira NM, Atayde IB, Brito e Silva MS. Evaluation of peritoneal adhesions formation and tissue response to polypropylene-poli(2-hydroxyethyl metacrylate)(polyHEMA) implanto $\mathrm{n}$ rat's abdominal wall. Acta Cir Bras. 2010;25(4):337-41.

20. Junge K, Rosch R, Krones CJ, Klinge U, Mertens PR, Lynen P, Schumpelick V; Klosterhalfen B. Influence of polyglecaprone 25 (Monocryl) supplementation on the biocompatibility of a polypropylene mesh for hernia repair. Hernia. 2005;9(3):212-7.

21. Bellón JM, Rodríguez M, García-Honduvilla N, Pascual G, Buján J. Partially absorbable meshes for hernia repair offer advantages over nonabsorbable meshes. Am J Surg. 2007;194(1):68-74.

22. Howdieshell TR; Webb WL; Sathyanarayana; McNeil PL. Inhibition of inducible nitric oxide synthase results in reductions in wound vascular endothelial growth factor expression, granulation tissue formation, and local perfusion. Surgery. 2003;133(5):528-37.

23. Orenstein SB, Saberski ER, Klueh U, Kreutzer DL, Novitsky YW. Efects of mast cell modulation on early host response to implanted synthetic meshes. Hernia. 2010; 14(5):511-6.

24. Binnebösel M, Klink CD, Otto J, Conze J, Jansen PL, Anurov M, et al. Impact of mesh positioning on foreign body reaction and collagenous ingrowth in a rabbit model of open incisional hernia repair. Hernia. 2010;14(1):71-7.

\section{Correspondence:}

Maria de Lourdes Pessole Biondo-Simões

Rua Ari José Valle, 1987

82030-025 Curitiba - PR Brasil

Tel./Fax: (55 41)3297.4359

malubiondo@gmail.com

${ }^{1}$ Research performed at Division of Experimental Surgery, Federal University of Parana (UFPR), Brazil. 